\section{Technology-based Learning Tools in Medical Lab Sessions}

Sir,

Student-learning through technology in medical schools has increased over time. Many medical institutions offer effective education using technological means. Many teaching methods have been adapted for the purpose, where learning is through technology focusing on understanding and application of the student's knowledge and skills through active, there and then, online examination with prompt results declaration giving them their percentage evaluation in the taught topic. ${ }^{1}$ Likewise, in the laboratory sessions, a few of the disciplines, especially pharmacology and physiology, have adopted various tools to deliver different medical concepts effectively and diligently. ${ }^{2}$ The purpose of utility of technology in teaching is to develop interesting ways for student's enhanced learning. ${ }^{3}$ These technology-based teaching methods include kahoot, model, and sketchy for more effective learning along with many other random programmes as design, gamification, social media, quizzes, blended learning, and available online learning resources. These methodologies are computer-based and hence, can enable us to obtain, store and review data on the systems effortlessly. ${ }^{4}$ At present, some teaching laboratories of different medical colleges in Pakistan are advanced to automation for the benefit of effective learning. Now, for laboratory sessions, any activity that uses computer programming for the record and retrieval of the data, helps to study the procedural outcome easily and is always available at the fingertip of the scientist. The practical works are accomplished through powerlab by connecting an instrument to the installed computer with a laboratory tutor or a laboratory diagram. The measured values are included in the powerlab software that creates various forms of graphics for better appreciation of the results. Powerlab is being used in frequently physiology and pharmacology laboratory sessions; and if biochemical analysis can also be done through these softwares, then innumerable results can be collected, stored and produced with their ample reflection in the test subjects effectively. This will require less time consumption and more precision and little training of the personnel handling it; while on the other hand, this will enhance capacity building, bringing swift and improved outcome for the betterment of mankind. ${ }^{5}$ Hence, e-learning is on the horizon and will produce the greater impact in lab teaching for the student's attentiveness, interest and enthusiasm in terms of communication and information technologies.

\section{CONFLICT OF INTEREST:}

Authors declared no conflict of interest.

\section{AUTHORS' CONTRIBUTION:}

SK, AK, SA: Contributed to the concept, design and flow of the research idea as well as writing of the manuscript and its final approval.

\section{REFERENCES}

1. Bouarab-Dahmani F, Tahi R. New horizons on education inspired by information and communication technologies. Procedia Soc Behav Sci 2015; 174:602-8.

2. Guze PA. Using technology to meet the challenges of medical education. Trans Am Clin Climatol Assoc 2015; 126:260-70.

3. López-Pérez MVPL, María C, Rodríguez-Ariza, Lázaro ArgenteLinares, Eva. The influence of the use of technology on student outcomes in a blended learning context. Educ Technol Res Dev 2013; 61:625-38.

4. Sadeghi R, Heshmati H. Innovative methods in teaching college health education course a systematic review. J Educ Health Promot 2019; 8:103.

5. Forrester, N.A.S.S, Recent developments in data recording systems for physiology. Pak J Physiol 2006; 2:1.

Sher Khan, Asra Khan and Saara Ahmad

Department of Biological and Biomedical Science, The Aga Khan University Hospital, Karachi, Pakistan

Correspondence to: Dr. Saara Ahmad Muddasir Khan, Department of Biological and Biomedical Sciences, The Aga Khan University Hospital, Stadium Road, Karachi, Pakistan E-mail: saara.muddasir@aku.edu

Received: January 04, 2020; Revised: July 19, 2019;

Accepted: July 27, 2019

DOI: https://doi.org/10.29271/jcpsp.2020.04.456 